\title{
MARGINALIDADE OU CIDADANIA? A REDE DISCURSIVA QUE CONFIGURA O TRABALHO DOS REDUTORES DE DANOS
}

\author{
Henrique Caetano Nardi \\ Rafaela de Quadros Rigoni"
}

\begin{abstract}
RESUMO. A revisão bibliográfica mostra que os estudos relativos à redução de danos (RD) se centram, predominantemente, na discussão das implicações de diferentes modelos de tratamento para o usuário de drogas e na redução de danos aplicada a usuários de drogas injetáveis. Porém, poucos estudos são encontrados acerca do trabalhador em RD. Neste contexto, o presente artigo propõe uma reflexão a respeito do trabalho dos redutores de danos, questionando como as formações discursivas sobre aids e drogas, na sociedade contemporânea, atravessam a subjetividade e o trabalho dos redutores, bem como sobre as possibilidades de inserção e sustentabilidade das ações em redução de danos.
\end{abstract}

Palavras-chave: Redução de danos, trabalho, subjetividade.

\section{MARGINALITY OR CITZENSHIP? THE DISCURSIVE NET THAT CONFIGURES THE WORK OF OUTREACH WORKERS}

\begin{abstract}
Scientific literature review shows that Harm Reduction (HR) articles focus mainly the discussion about the implications of different drug users treatment models and the efficiency of HR with injection drug users. However, there are few studies about HR workers. In this context, the present article aims to discuss the work of outreachworkers, proposing an analysis of how the discursive formations about drugs and Aids, in contemporary society, influence the work and the subjectivity of the outreachworkers, as well as the possibilities of having "sustainable projects" as a way to include harm reduction practices in public health services.
\end{abstract}

Key words: harm-reduction, work, subjectivity.

A inserção de ações em redução de danos (RD) como programa de saúde é relativamente nova: pouco mais de duas décadas de inserção internacional e apenas dez anos no Brasil em caráter oficial, apesar de algumas iniciativas, interrompidas por medidas legais, datarem de 1989, como veremos mais tarde. Os primeiros estudos científicos acerca do tema foram publicados no início da década de 1990 e, desde então, a produção de trabalhos tem aumentado consideravelmente.

A revisão da literatura científica mostra que a maioria dos estudos, nacionais e internacionais, centra-se predominantemente em dois campos: o da discussão das implicações das políticas de adoção de diferentes modelos de tratamento para o usuário de drogas, comparando o modelo médico e a estratégia da redução de danos: Heller, McCoy e Cunningham (2004); Bastos, Karam e Martins (2003), e o da redução de danos aplicada a usuários de drogas injetáveis: Rhodes, Davis e Judd (2004); Hacker, Telles e Bastos (2001). Não obstante, poucos estudos discutem o trabalho e os trabalhadores em redução de danos - os redutores de danos ou outreachworkers (Iinsua \& Moncada, 2003; Strike, O'Grady, Myers \& Millson, 2004). Assim, buscou-se neste artigo focalizar esse aspecto essencial da RD, levando-se em conta as práticas, o contexto social/cultural de seu trabalho, o atravessamento dos discursos em torno da aids e das drogas e a constituição da subjetividade dos trabalhadores.

\footnotetext{
* Professor do Departamento de Psicologia Social e Institucional e do Programa de Pós-Graduação em Psicologia Social e Institucional da Universidade Federal do Rio Grande do Sul.

\# Mestranda pelo Programa de Pós-Graduação em Psicologia Social e Institucional, Universidade Federal do Rio Grande do Sul e membro da Organização Não-Governamental Movimento Metropolitano de Redução de Danos.
} 


\section{UMA ESTRATÉGIA CHAMADA "REDUÇÃO DE DANOS"}

A redução de danos (RD) pode ser definida como um conjunto de medidas em saúde que tem a finalidade de minimizar as conseqüências adversas do uso/abuso de drogas. Tais ações possuem como princípio fundamental o respeito à "liberdade de escolha", porquanto, mesmo que nem todos os usuários consigam ou desejem abster-se do uso de drogas, preconiza-se, como medida de saúde, a redução dos riscos de infecção pelo HIV e hepatite (MS, 2001). Outro princípio da RD refere-se à possibilidade do usuário de drogas refletir sobre o que é melhor para sua saúde, fazer escolhas de acordo com seu julgamento - apesar de saber-se que isso não é possível em todos os casos - afirmando a responsabilidade do indivíduo em relação ao seu tratamento e ao uso de drogas (Cruz, 2000).

Além da RD, duas outras estratégias são tradicionalmente adotadas pelas políticas relativas às drogas no Brasil: a da oferta de drogas e a da redução da demanda. A primeira se preocupa em destruir plantações e princípios ativos, reprimir a produção e o tráfico, combater a "lavagem" de dinheiro e controlar e fiscalizar a produção, a comercialização e o uso das drogas; a segunda procura desestimular ou diminuir o consumo e a iniciação nas drogas e tratar usuários dependentes tendo como meta indispensável a abstinência.

Existem discussões sobre ampliação do conceito de $\mathrm{RD}$, como, por exemplo, a tentativa de aplicá-lo ao trabalho com trabalhadores intoxicados por substâncias utilizadas em processos industriais (como o mercúrio) ou por agrotóxicos em plantações; de pessoas que usam anabolizantes; de travestis que injetam silicone sem um adequado acompanhamento médico, entre outros. Este tipo de trabalho ainda é pouco desenvolvido no Brasil, e este conceito ampliado em RD se encontra em construção. Neste artigo, iremos discutir somente as ações de RD em relação ao uso indevido de drogas, entendendo-se como drogas tanto as consideradas lícitas quanto as ilícitas.

Para que se possa compreender como o trabalho em RD é atravessado pela rede enunciativa que conforma o discurso sobre a aids, as drogas e o trabalho na sociedade contemporânea, objetivo deste artigo, utilizaremos de forma sucinta o recurso genealógico de Foucault (1971) para delimitar seus contornos históricos.

A RD teve origem na Inglaterra em 1926, com o relatório Rolleston, que estabelecia a possibilidade de o médico prescrever, legalmente, opiáceos para dependentes desta droga como parte do tratamento.
Não obstante, somente na década de 1980 as ações baseadas neste princípio foram sistematizadas em programas. O primeiro surgiu na Holanda, por iniciativa de uma associação de usuários de drogas preocupados com os índices de transmissão de hepatite B entre usuários de drogas injetáveis (MS, 2001). O método de prevenção utilizado nesse país era a troca de seringas. Já nos países onde a troca era considerada ilegal, como no início dos programas de RD no Brasil, o método de prevenção utilizado era a desinfecção das seringas com uma solução de hipoclorito de sódio. A proposta atual consiste no nãocompartilhamento de seringas entre usuários, os quais deveriam trocar as usadas por novas. Conforme Bastos, Karam e Martins (2003), somente com a entrada de profissionais da saúde na RD vinculou-se a troca de seringas à prevenção do HIV. Com esta atuação, a RD acabou conquistando um espaço de trabalho que ficou vinculado aos programas de prevenção às DSTs/Aids.

No Brasil, a primeira tentativa de fazer troca de seringas ocorreu em 1989 em São Paulo; entretanto não houve continuidade, devido a uma interdição judicial (Bueno, 1998). Somente a partir de 1995 foi possível realizar as trocas legalmente, de início em Salvador, e em 1998, em São Paulo, quando foi sancionada uma lei autorizando os programas de RD no Estado (MS, 2001). No Rio Grande do Sul, o primeiro programa de troca de seringas data de 1996, em Porto Alegre; entretanto, a oficialização do trabalho só aconteceu três anos depois, com a aprovação do Projeto de Lei n. ${ }^{\circ} 169 / 99$ (Brasil, 1999).

Deste movimento de implantação de ações de RD participaram ONGs e OGs (organizações nãogovernamentais e governamentais), o Ministério da Justiça, o Programa Nacional e as Coordenações Estaduais e Municipais de DSTs/aids. Hoje, vários estados e municípios possuem leis que legalizam o trabalho de redução de danos e o Ministério da Saúde apóia e financia ações em RD em todo o país, como pode ser comprovado pelas diretrizes da atual Política do Ministério da Saúde para a Atenção Integral a Usuários de Álcool e Outras Drogas (MS, 2003), pela legislação recente que decreta a inserção da $\mathrm{RD}$ na atenção básica e secundária (MS, 2004a) e pelos 147 projetos em RD em andamento, financiados pelo Ministério da Saúde no Brasil (MS, 2004b).

Hoje, o trabalho em redução de danos já conquistou um espaço de atuação mais amplo do que a prevenção entre usuários de drogas injetáveis, abrangendo usuários de diferentes drogas, como crack, álcool, cocaína aspirada, maconha, loló. A distribuição ou troca de cachimbos (para usuários de 
crack), o kit snif (para cocaína aspirada) e estratégias de diminuição, substituição ou cuidados no uso são aplicadas para reduzir os danos mediante a negociação de "contratos terapêuticos" firmados entre os redutores e os usuários no campo. Porém, apesar dos avanços conquistados, ainda nos deparamos com o preconceito e com dificuldades em relação à inserção institucional da RD no sistema de saúde e nas políticas sobre drogas.

\section{ENTRE A MARGINALIDADE E A CIDADANIA - O AGENTE REDUTOR DE DANOS}

Os Programas de Redução de Danos (PRDs) são a forma predominante de implementação da estratégia da redução de danos no Brasil e

$$
\begin{aligned}
& \text { (...) consistem em um elenco de ações } \\
& \text { desenvolvidas em campo por agentes } \\
& \text { comunitários de saúde especialmente } \\
& \text { treinados (denominados 'redutores de danos' } \\
& \text { ou simplesmente 'redutores'), que incluem a } \\
& \text { troca e distribuição de seringas, atividades de } \\
& \text { informação, educação e comunicação (IEC), } \\
& \text { aconselhamento, encaminhamento, vacinação } \\
& \text { contra hepatite e outras ações. (MS, 2001, } \\
& \text { p. } 12 \text { e 13). }
\end{aligned}
$$

Estes programas podem ser executados por OGs ou ONGs e geralmente contam com um coordenador e redutores contratados, os quais dividem seu trabalho em áreas da comunidade, cada uma constituindo um "campo" diferenciado. O trabalho do redutor de danos envolve o contato direto com a comunidade, onde desempenha um papel de educador em saúde na prevenção às DSTs, HIV/aids, hepatite e outras doenças ligadas direta ou indiretamente ao uso/abuso de drogas. O redutor opera num sentido de "busca ativa" dos usuários de drogas, mapeando suas redes sociais, locais de uso, práticas de risco, sempre amparado na formação de um vínculo com o usuário. É através deste vínculo que os redutores realizam os "contratos terapêuticos" com os usuários em campo: combinações que passam pela troca de insumos (seringas, cachimbos, distribuição de preservativos) e encaminhamentos, sempre respeitando o momento e a vontade do usuário, onde pouco a pouco se estabelecem formas de "cuidado de si" que perpassam tanto o usuário quanto o próprio redutor.

Os sentidos atribuídos à soropositividade e ao uso de drogas são fatores centrais na configuração do trabalho do redutor. Sendo assim, compreendemos que os modos de trabalhar e a produção da subjetividade destes trabalhadores são atravessados pelas formações discursivas (Foucault, 1997) que conformam os jogos de verdade acerca das drogas e seus usuários, da aids e seus portadores, além, é claro, da nova configuração do mercado de trabalho derivada das transformações do capitalismo nos últimos trinta anos.

Partiremos, então, para identificar esses jogos de verdade, o que nos auxiliará a entender como os saberes estão imbricados nas relações de poder em determinadas circunstâncias históricas, as quais vão implicar em determinados cuidados de si. Para identificarmos como os saberes se constituíram, devemos analisar as condições que permitiram seu surgimento num determinado tempo e espaço e definir quais enunciados correspondem às formações discursivas (Foucault, 1997) relativas à Aids, às drogas e ao trabalho.

Em nossa sociedade o usuário de droga e a droga (especialmente as ilícitas) não possuem uma visibilidade positiva. As regras de enunciação a respeito das drogas se aproximam daquelas que definem a marginalidade e o tráfico, compondo o código moral que localiza o "mal" nos indivíduos. Estes atravessamentos discursivos adquirem materialidade no preconceito verbalizado em relação ao trabalho com RD, como, por exemplo, quando se externaliza o argumento de que a troca de seringas ou cachimbos é um incentivo ao uso de drogas. Neste sentido, o trabalho do redutor passa a ser confundido com a ilegalidade e a marginalidade, e o próprio redutor pode ser visto como alguém "suspeito", e não como um agente/trabalhador da saúde.

Distintas redes enunciativas dão suporte ao aparato legal e científico acerca do binômio drogas/aids. Nesta direção Picollo (2001) afirma que diversos agentes colaboram para a construção da "droga" enquanto um problema social, entre eles, os agentes políticos, repressivos, terapêuticos e midiáticos.

A política de drogas no Brasil tem sido conduzida por várias instâncias: a SENAD (Secretaria Nacional Antidrogas) e diferentes Ministérios (Saúde, Educação e Justiça), pelos CONENs (Conselhos Estaduais de Entorpecentes), COMENs (Conselhos Municipais de Entorpecentes) e pela sociedade civil organizada. Tal diversidade se reflete na legislação e nas políticas sobre drogas, as quais possuem orientações até certo ponto controversas. A SENAD, órgão responsável pela PNAD (Política Nacional Antidrogas), por exemplo, é ligada ao Gabinete de Segurança Institucional e dirigida por um representante das Forças Armadas. A orientação desta política é a redução da demanda e da oferta de drogas, tendo como pressuposto básico alcançar uma sociedade "livre das drogas" e a "busca da conscientização do 
usuário de drogas ilícitas acerca de seu papel nocivo ao alimentar as atividades e organizações criminosas" (Brasil, 2004, p.13 e 14). De encontro a estes pressupostos, a PNAD reconhece a estratégia da RD como intervenção preventiva que deve ser incluída entre as medidas a serem desenvolvidas, sem prejuízo das outras modalidades (Brasil, 2004). Para a RD, o uso de drogas sempre existiu na sociedade, portanto, uma sociedade livre das drogas seria utópica. Além disso, seu objetivo é o resgate da cidadania do usuário, e não sua culpabilização. Assim, vemos convergirem num mesmo documento orientações com princípios bastante diversos.

Ainda como marcador da rede enunciativa, encontramos na legislação brasileira a Lei de Entorpecentes, que define o uso de drogas como crime e/ou doença, prevendo cumprimento de pena no sistema penitenciário e/ou tratamento para recuperação da dependência (Brasil, 1976). A lei condena o uso, a produção e o consumo de certos tipos de substâncias (dividindo as drogas em lícitas e ilícitas), e coloca o usuário, o produtor e o comerciante das chamadas drogas ilícitas em uma posição de "fora da lei", de marginal. Apesar das tentativas de atualização desta lei ${ }^{1}$ - que buscam a criação de um Sistema Nacional de Políticas Públicas sobre Drogas (SISNAD), a reinserção social de usuários e dependentes de drogas, a opção por uma política de redução de riscos e a retirada do tratamento como pena (Câmara dos Deputados, 2004) - as críticas à eficácia do projeto de lei continuam, pois não há critérios objetivos de diferenciação entre quantidade para uso e para tráfico, nem entre grandes chefes do tráfico e os "aviões", mantendo-se o porte ou uso de drogas como crime sujeito a penalidades (IBCCRIM, 2004). A idéia é promover uma "descarcerização" do usuário, mas não uma descriminalização. O usuário é, assim, ainda entendido na posição de "fora da lei".

Em uma direção diversa, a Política do Ministério da Saúde para a Atenção Integral a Usuários de Álcool e outras Drogas traz em suas diretrizes o apoio à implementação da RD como alternativa às propostas "de caráter total, fechado e tendo como único objetivo a ser alcançado a abstinência” (MS, 2003, p.5). De acordo com este documento, para que uma política de saúde seja coerente, eficaz e efetiva, deve ter em conta que distintas estratégias (como o retardo do consumo,

Uma primeira tentativa ocorreu com o Projeto de Lei n. 7.134-A, de 2002 - substitutivo que não foi aprovado. Uma segunda tentativa ocorre agora com o Projeto de Lei n. 7.134-B (Câmara dos Deputados, 2004) que no momento, já aprovado pela Câmara de Deputados, tramita para votação no Senado Federal. redução de danos do consumo e a superação do consumo) são complementares, e não concorrentes (MS, 2003).

Nesta mesma direção temos a Portaria n. ${ }^{\circ} 2.197$, que redefine e amplia a atenção integral para usuários de álcool e outras drogas no âmbito do SUS (Sistema Único de Saúde). Este "preconiza" a adoção da lógica de redução de danos na Atenção Básica, nos CAPSad's (Centros de Atenção Psicossocial em Álcool e Drogas), ambulatórios e outras unidades especializadas. A Portaria prevê ainda a criação do Serviço Hospitalar de Referência em Hospitais Gerais, para dar suporte à demanda gerada em outras instâncias de atendimento, evitando a internação de usuários em hospitais psiquiátricos (MS, 2004b). Além disso, espera-se que o Ministério da Saúde mantenha a Portaria n. 1028 de 01/07/2005, que regulamenta as ações de $\mathrm{RD}$ no âmbito da saúde pública. Tal portaria esperava assinatura desde 2003, e foi finalmente assinada em 01/07/2005 e divulgada no dia 4 de julho juntamente com outras legislações ${ }^{2}$. Infelizmente tal conquista, fortemente festejada pelo movimento RD, durou pouco: dias depois, todas as portarias foram suspensa ${ }^{3}$, e aguardam novo resolução.

Neste contexto, a construção social/legal proibitiva em torno do uso/produção/venda de drogas ainda configura o trabalho do redutor de danos como um trabalho de risco, por exemplo, quando o trabalhador tem que entrar em locais que não conhece, quando não é morador da comunidade onde atua, quando não conhece previamente os usuários e/ou não tem "acesso liberado" aos pontos de uso e venda de drogas. Nestas ocasiões as tarefas de "abrir campo" conhecer e ser conhecido pela comunidade estabelecendo uma relação de trabalho - e identificar os usuários podem trazer algumas dificuldades, como áreas "proibidas" e problemas com o tráfico local. Além desses riscos, existem situações de confronto com a polícia, pois, apesar da existência de proteção legal, existem relatos de lesões corporais e detenção destes trabalhadores em razão do material que

\footnotetext{
Portaria n. 1027, de 01/07/2005, que prevê o tratamento de urgências, overdoses e internações de até 15 dias de usuários de álcool e outras drogas em hospitais gerais, para municípios acima de 200 mil habitantes; Portaria n. 1059, de $04 / 07 / 2005$, que destina incentivo financeiro de $\mathrm{R} \$$ $50.000,00$ para os CAPSad em funcionamento para a implementação de ações de RD; Portaria n. 384, de 05/07/2005, que autoriza os CAPS I ampliarem sua oferta de atendimento para usuários de álcool e outras drogas.

3 Portaria n. 1187, de 13/07/2005, que suspende por até 30 dias o efeito das portarias para impactos financeiros e apreciação da Comissão Intergestores Tripartite
} 
carregam (seringas, cachimbos) e da suspeita acionada pelos locais onde andam (locais de uso e tráfico de drogas).

Levando em conta, então, os enunciados que conformam um contexto proibitivo/repressivo em torno das drogas e seus usuários, juntamente com algumas conquistas do movimento da R D em termos de decretos e leis que dão algum suporte às práticas, poderíamos afirmar que também o trabalhador em redução de danos fica preso em uma posição ambivalente, ora vendo-se (e sendo visto) como trabalhador da saúde, ora numa condição de marginalidade e sem garantias para executar seu trabalho? Voltaremos a este ponto quando tratarmos mais especificamente da precariedade do vínculo que configura o redutor enquanto trabalhador.

Esta diversidade presente nas políticas se associa aos diferentes modelos terapêuticos (e seus enunciados) que vêm sendo utilizados para "dar conta" do uso/abuso de drogas. Cruz (2000) nos chama a atenção para o fato de que foi somente a partir do século passado que o uso abusivo de substâncias psicoativas passou a ser definido como um problema médico: antes a questão tinha explicações de cunho moral e religioso - dependentes e usuários eram os vagabundos, imorais, pessoas do mal (será que mudamos muito?). Com o modelo médico o uso/abuso de drogas passou a ser visto como doença, inicialmente determinada exclusivamente pelo seu caráter biológico, mais tarde ampliando-se para as dimensões social e comportamental, contempladas nos manuais como o CID-10 (Código Internacional de Doenças - 10) e DSM-IV (Diagnostic and Statistical Manual of Mental Disorders). Neste modelo o usuário/abusador passa a ser considerado doente, incapaz de responder por suas escolhas, devendo ser orientado por um especialista que deve saber o melhor para sua saúde.

Assim, os modelos de tratamento que trabalham com o imperativo da abstinência podem produzir a segregação de cidadãos usários de drogas, principalmente das que são ilícitas, inviabilizando o acesso e acolhimento dos usuários de drogas nos serviços de saúde, a partir de uma posição julgadora dos profissionais. Além disso, uma política que é repressiva em relação às drogas é atravessada pela lógica do biopoder (Foucault, 2001), entendido como política de controle das populações pelo Estado, realizando uma homogeneização de todos a partir da necessidade indistinta de abstinência.

Neste sentido, cada um dos modelos de tratamento para o uso/abuso de drogas produz um conhecimento que se traduz em verdades acerca do usuário, seu corpo, sua moralidade, suas formas de ser. Foucault afirma que a verdade está em relação direta com as tramas do poder, sendo que “... não é a atividade do sujeito de conhecimento que produziria um saber, útil ou arredio ao poder, mas o poder-saber, os processos e as lutas que o atravessam e que o constituem, que determinam as formas e os campos possíveis do conhecimento" (Foucault, 1996, p.30). Todo saber, portanto, origina-se em relações de poder e é político: para que um saber exista devem existir condições políticas necessárias à sua "legitimação". Temos, então, que as relações de poder e saber - no caso, referentes a algumas formas do fazer em saúde investem os corpos humanos e os submetem, fazendo deles objetos de saber. Cabe ressaltar que, para Foucault, onde existe poder está também presente a resistência, a qual possibilitaria, por exemplo, em determinados momentos e contextos históricos, o surgimento de novos modos de lidar com a questão do uso/abuso de drogas.

Em uma tentativa de ir além do modelo de doença com suas possíveis implicações de inexistência ou abrandamento da responsabilidade daquele que está doente sobre o que lhe acontece, buscam-se outros modos de intervenção. Conte (2004) nos mostra que, mesmo em casos de toxicomania (dependência), a não-obrigatoriedade da abstinência no tratamento traz valiosos benefícios, como a possibilidade de se estabelecer um vínculo terapêutico e se produzir uma ressignificação da experiência com as drogas. Comparando a abordagem tradicional (de abstinência) com a abordagem da RD, Wodak afirma que a primeira "vê os usuários de drogas como marginais frente à sociedade, apenas aceitáveis desde que livres das drogas", enquanto a RD "vê os usuários de drogas como membros da sociedade, almeja reintegrá-los à comunidade" (Wodak, 1998, p.57). Neste sentido, a rede enunciativa que define a RD e, por conseqüência, o trabalho do redutor, se apóia na promoção do exercício da cidadania do usuário, o que significa o reconhecimento, em primeiro lugar, da condição de cidadão portador de direitos, antes da condição de usuário de drogas na sociedade. Não se impõe a abstinência, mas se afirma a importância de se avaliarem os riscos que são, sem dúvida, reais. De acordo com Acselrad (2000), trata-se de uma "educação para autonomia", em que, ao invés de se identificar qualquer tipo de uso com o uso dependente, esclarecem-se as diferentes relações estabelecidas com a droga e as diferentes possibilidades de ação educativa: no uso não dependente poderia se trabalhar a percepção dos riscos e o acompanhamento, ao invés de medicalização e ação policial; no uso dependente, 
um apoio na formulação da demanda de tratamento e do encaminhamento, respeitando particularidades, mantendo uma relação de confiança e acompanhamento, desfazendo terrores e discriminações ${ }^{4}$.

Além disso, as práticas dos redutores buscam valorizar o saber da população com a qual trabalham os usuários de drogas - para o planejamento e ações de intervenção, buscando uma discussão coletiva e não restrita ao campo das disciplinas e experts. Vale dizer também que muitos redutores são usuários ou ex-usuários de drogas, em função da estratégia de trabalho com pares pelo conhecimento da linguagem, estratégias e necessidades da população com a qual trabalham. Esta configuração também se deve a um dos modos de trabalho da RD: muitos redutores iniciaram sendo atendidos pelos PRDs, passaram por um tipo de trabalho voluntário como "amigos do projeto" e, após um tempo, foram admitidos como redutores nos programas. Esta trajetória possibilita que o usuário passe a ocupar outro lugar, aproveitando sua experiência de vida enquanto usuário para o cuidado com outros usuários em campo. Trata-se de uma possibilidade de ressignificação desta experiência, da utilização deste saber em prol de si e do outro.

Nossa hipótese é que a RD, ao buscar romper com os modelos anteriores, desconstrói verdades e possibilita a emergência de novas formas de ação em relação ao uso/abuso de drogas. Nesta mesma direção, Brasil (2003) propõe que a RD seja compreendida como um dispositivo que se diferencia dos modos de intervir que exercitam técnicas de biopoder, posto que não estabelece relações com os usuários pela via da moral, do ressentimento ou do resgate de um estado de saúde ideal estabelecido pela norma médica. A partir dessas noções, poderíamos então pensar a inserção da RD e o trabalho dos redutores como um movimento de resistência a um discurso/modo de subjetivar dominante e como uma forma de construção de cidadania.

Podemos ainda pensar, para além das possíveis produções discursivas aqui discutidas, que outras lógicas se processam quando se alia o discurso em

4 Apesar da diferenciação feita pela autora, julgamos importante fazer uma ressalva sobre a dificuldade de se estabelecer um limiar preciso entre um uso dependente $\mathrm{e}$ um não dependente.

5 O "amigo do projeto" é uma pessoa dentro da comunidade que se dispõe a auxiliar o redutor em seu trabalho, guardando materiais (seringas, cachimbos) em sua casa para trocas em horários que o redutor não se encontra no campo, e ainda para acessar os usuários que (ainda) não querem aparecer para o PRD. torno do uso das drogas à preocupação com a aids. Sabe-se que ainda encontramos no imaginário social a representação da aids como "castigo divino", como mais uma alegação de "culpado", dependendo a forma de contágio - as "vítimas inocentes" pela transmissão através do parto ou por transfusões de sangue; e os "culpados", pela transmissão por via sexual ou uso de drogas- (Piccolo, 2001). Neste sentido, a aids foi utilizada para reforçar o cerco sobre os desviantes, denunciando pessoas com comportamentos distintos daqueles socialmente aceitos. Profissionais do sexo, homens que fazem sexo com homens e usuários de drogas foram duplamente culpabilizados por seu comportamento.

Aqui vemos convergir a "anatomia política" da disciplinarização dos corpos a partir de uma "teoria geral do adestramento" e os dispositivos biopolíticos preocupados com as intervenções e controles reguladores da vida. Neste sentido, o biopoder produz a normalização do viver, engendrando o corpo vivo em mecanismos contínuos, operando distribuições em torno da polarização normalidade/anormalidade (Foucault, 2001).

A aids, então, engendrada neste complexo de relações de poder-saber, foi construída socialmente como uma "epidemia das anormalidades sexuais", e a morte de seus portadores também foi social, atravessada pelo estigma e preconceito.

Lembrando que, para Foucault, na análise do campo discursivo

(...) trata-se de compreender o enunciado na estreiteza e singularidade de sua situação; de determinar as condições de sua existência, de fixar seus limites de forma mais justa, de estabelecer suas conexões com outros enunciados a que pode estar ligado, de mostrar que outras formas de enunciação exclui (Foucault, 1997, p.31),

podemos pensar, então, em quais fatores criaram as possibilidades de inserção da aids nos modos de tratamento em relação ao uso/abuso de drogas e nas formações discursivas desta nova estratégia chamada redução de danos. A RD se instituiu intimamente ligada aos programas de prevenção às DSTs/aids como uma estratégia de prevenção, principalmente em relação às trocas de seringas, quando se percebeu que os casos de transmissão de HIV através do uso de drogas injetáveis notificados em 1992 eram da ordem de 28,9\% do total de casos, sendo muitos dos casos de transmissão indiretamente ligados a este uso, através da transmissão sexual para parceiros(as) de usuários. 
Com a diminuição do uso de drogas injetáveis e o aumento de outras, como o crack, e mesmo a preocupação crescente com as drogas "lícitas" álcool, tabaco, psicofármacos, anabolizantes - abriu-se o campo de atuação da RD. Mesmo assim, esta estratégia permaneceu fortemente ligada à aids. Vale lembrar que o vínculo da RD com a aids se refere também à sustentabilidade dos programas de redução de danos, que dependem, em grande parte, do financiamento oriundo do Programa Nacional de DSTs/aids.

Foucault nos lembra que há um campo de controle dos discursos através de procedimentos de exclusão pelos quais a interdição, a rejeição e o sistema de verdadeiro e falso estabelecem quais pessoas e/ou discursos podem ser ouvidos, que palavras podem ser escutadas ou rejeitadas, enfim, qual é o discurso "verdadeiro". Para ser considerado verdadeiro, o discurso deve ser pronunciado por quem de direito e conforme o ritual requerido, o que implica em uma "vontade de verdade". Esta se liga à nossa "vontade de saber" e se apóia num suporte e distribuição institucionais, tendendo a exercer sobre os outros discursos uma pressão, como que uma espécie de coerção, "como se a própria palavra da lei não pudesse mais ser autorizada, em nossa sociedade, senão por um discurso de verdade" (Foucault, 1999, p.19). Neste sentido, a forte ligação da RD com a aids parece servir, dentre outros, como uma possibilidade de legitimar novas formas de ver e trabalhar com o usuário de drogas numa sociedade onde o interesse no cuidado ao usuário começa quando este passa a oferecer algum risco à população "normal".

Por um lado, a Aids possibilitou a visibilidade das práticas do uso de droga injetável e de seus usuários, chamando a atenção para a necessidade de outros tipos de intervenção ligados à saúde para este público. Neste sentido, a prevenção da contaminação pelo vírus serve de argumento para legitimar as práticas dos redutores, facilitando a aceitação desta estratégia. Além disso, as ações relacionadas à prevenção do HIV/Aids, extremamente normalizadoras num momento inicial, transformaram-se a partir da pressão dos movimentos sociais, levando à discussão atual em torno do combate à vulnerabilidade, em uma perspectiva que se aproxima da proposta da RD. Por outro lado, o argumento centrado exclusivamente na prevenção do HIV/aids acaba por colocar em segundo plano a "cidadania do usuário" e a legitimidade de outras ações já realizadas pelos redutores (como a troca de cachimbos e os encaminhamentos para o SUS, não relacionados ao HIV/aids). Além disso, a focalização exclusiva na aids desconsidera questões de caráter mais amplo, ligadas a transformações nas políticas públicas. Segundo Coppel e Doubre (2004), limitar a redução de danos à suas ações de controle do risco de infecção (ao HIV e outras doenças transmissíveis) significa barrar as possibilidades de mudança nas políticas de drogas.

Por fim, podemos ainda nos questionar sobre o que acontece quando, em meio a esta complexidade de atravessamentos dos enunciados a respeito das drogas e da aids, consideramos aqueles referentes ao lugar e aos modos de trabalho e de trabalhadores. Sabemos que o contexto do mundo do trabalho contemporâneo, com suas novas formas de gestão, nos traz enunciados de valorização do individualismo e da competição, e que estas mesmas formas levaram a um incessante aumento do desemprego e da precarização do trabalho. Neste sentido, podemos pensar nos questionamentos atuais acerca da sustentabilidade das ações em redução de danos. O financiamento das ações de RD a partir de projetos - com duração de um ano e possibilidade de aditamento por mais um - não possibilita um planejamento a longo prazo, nem por parte da organização (e por consequiência de quem ela atende), nem por parte dos trabalhadores, que, como trabalhadores do chamado " $3^{\circ}$ Setor", não possuem as garantias da legislação trabalhista como férias, $13^{\circ}$ salário, seguro desemprego, auxílio-doença e o benefício e a proteção relativas aos acidentes de trabalho.

$\mathrm{Na}$ tentativa de garantir uma maior sustentabilidade das ações e dos trabalhadores em $\mathrm{RD}$, vêm sendo produzidas novas formas de organização do trabalho. Além dos programas/projetos de redução de danos financiados por agências, vem-se buscando a inserção da RD no SUS, o que pode auxiliar na construção de formas mais estáveis de contratação para os trabalhadores. Uma destas formas de inserção em espaços instituídos é a inserção das ações em RD nos serviços da Atenção Básica em Saúde do SUS, ou seja, nas unidades de saúde (US) e programas governamentais de PACS/PSF (Programa de Agentes Comunitários de Saúde e Programa de Saúde da Família). Tal inserção pode acontecer através de aproximações entre redutores de danos e as USs, ou mesmo por meio de ações diretas dos agentes comunitários de saúde (ACS $)^{6}$, facilitando o acesso e a aproximação do usuário ao sistema de saúde.

6 O trabalho conjunto de ACS e redutores possibilita encaminhamentos e a aplicação dos princípios da RD nos atendimentos familiares cotidianos realizados pelo ACS, ampliando a cobertura das ações em RD, bem como possibilitando um contato mais amplo com a população, incluindo toda a família e facilitando o acesso também aos usuários das chamadas drogas lícitas (álcool, tabaco, medicamentos). 
Outra forma de parceria se dá através da contratação do redutor de danos via PACS/PSF como um agente comunitário especial; porém este tipo de contratação traz em si um risco, que é a perda da especificidade do trabalho do redutor de danos, caso o redutor tenha de assumir as funções de um ACS além das de RD. A resistência em relação a contratações deste tipo diz respeito também à tentativa de manutenção de uma identidade profissional, já que a pouca institucionalização da prática de $\mathrm{RD}$, aliada a uma perda de especificidade do trabalho, poderia diluir suas práticas, tornando ainda mais difícil a afirmação desta proposta.

Há ainda a possibilidade da contratação dos trabalhadores pela prefeitura das cidades através do Plano de Ações e Metas (PAM), o que pode ser feito mediante a terceirização do serviço de redução de danos por meio do contrato com uma ONG que gerencie a contratação dos trabalhadores que irão executar as ações. Pode-se também, através do PAM, estruturar um serviço de RD dentro da organização governamental, por exemplo, ligado a um serviço de aids. Porém, na contratação mediante qualquer uma das formas acima citadas, as ações e os trabalhadores em RD ainda ficam sujeitos às oscilações das gestões políticas e às aprovações anuais de orçamentos e projetos, continuando sem garantias trabalhistas em função de serem contratados como autônomos.

Castel (1998) demonstra que um dos efeitos das novas configurações do capitalismo é a produção não somente de uma periferia precária, mas também da "desestabilização dos estáveis", ou seja, o aparecimento de uma zona de vulnerabilidade, alimentada pela precarização, a qual produz, no final do percurso, o desemprego e a desfiliação (pessoas expulsas da produção pelo desemprego e subemprego). Conforme o autor, uma das conseqüências dos processos de desfiliação é a perda dos suportes sociais que garantem a igualdade de direitos em uma sociedade democrática e possibilitam ao trabalhador ter a propriedade de si (de seu corpo, de seu tempo) e pensar o próprio destino. Neste sentido, a destruição destes suportes sociais acaba por limitar a liberdade do trabalhador, posto que o corpo e o tempo lhe são desapropriados, inviabilizando uma reflexão e planejamento do amanhã, bem como de sua própria subjetividade (modos de ser, de trabalhar), que deve ser moldada para adaptar-se às condições do mercado de trabalho.

Podemos pensar o que acontece, então, quando se aliam à precarização do trabalho e à desfiliação os enunciados referentes às drogas e aids na sociedade. Talvez o fato de os redutores não terem nenhuma garantia salarial, dependerem de verbas que podem ou não chegar, não terem férias nem carteira assinada e ganharem pouco acima do salário-mínimo para trabalhar em torno de 20 horas semanais (acordo feito com as ONGs), possa ter alguma ligação com o tipo de trabalho que desenvolvem, ou melhor, com o tipo de pessoas que envolvem em seu trabalho. Além deste caráter precário, como a negociação da contratação dos serviços envolve o gestor local, inúmeras vezes secretários de saúde, prefeitos ou mesmo coordenadores de PACS/PSF são resistentes à proposta da RD pela "má impressão" que causaria nos eleitores o investimento do dinheiro da saúde "neste tipo" de trabalho. Neste sentido, estas tentativas (e dificuldades) para "profissionalizar" a "categoria" dos redutores parecem ser também atravessadas pelos discursos sobre drogas e aids.

Podemos, então, problematizar a forma como os redutores de danos podem fazer a experiência de si mesmos e de seu trabalho dentro dos jogos de verdade que são produzidos pela rede enunciativa que constrói o lugar da RD.

A partir do mote "assuma o controle", a RD propõe aos usuários que decidam por si mesmos se devem cuidar ou não de si e de que forma fazê-lo, de modo que a questão que interessa não é a noção de desvio, mas a de excesso ou moderação, de ser mestre ou escravo de seu próprio desejo. Neste sentido, podemos pensar que a $\mathrm{RD}$ e os redutores buscam veicular uma ética ${ }^{7}$ em que o cuidado de si se coloca como uma escolha estética ou política, e não como uma imposição. Porém, assim como Foucault, pensamos que o cuidado de si se constrói na relação com o outro. Neste sentido, a tarefa inicial do redutor de danos, para poder realizar contratos terapêuticos com os usuários no sentido de que estes "assumam o controle", é aprender a governar-se, refletir sobre sua vida e suas implicações com a perspectiva de trabalho que guiará suas ações.

\footnotetext{
Para Foucault a ética é o tipo de relação que se deve ter consigo mesmo e que determina a maneira pela qual o indivíduo deve se constituir a si mesmo como o sujeito moral das próprias ações. Esta relação consigo mesmo possui 4 aspectos principais: o primeiro aspecto é a substância ética - a parte de nós ou de nosso comportamento que importa à conduta moral; o segundo é o modo de sujeição - maneira pela qual as pessoas são incitadas a reconhecer suas obrigações morais; o terceiro se refere às práticas de si ou ascetismo - os meios pelos quais podemos nos modificar para nos tornarmos sujeitos éticos; por fim, o quarto aspecto se refere à teleologia - o tipo de ser a que aspiramos quando nos comportamos de acordo com a moral (Dreyfus \& Rabinow, 1995, p.262-265).
} 
Segundo Foucault (2001), a prática reflexiva da liberdade é a postura ética que possibilita ao sujeito decidir sobre o próprio destino, e isso se dá pela decifração dos jogos de verdade que o atravessam, permitindo assim jogar num nível mínimo de dominação. Para o trabalhador que busca produzir possibilidades de o usuário que atende poder "cuidar de si", o cuidado do trabalhador consigo mesmo é fundamental. Porém, considerando-se o contexto em que trabalham os redutores, convivendo com a insegurança derivada da falta de garantias, aliada ao possível confronto com o próprio uso de drogas, como poderiam eles vivenciar o cuidado de si e exercer sua cidadania para, então, operarem nesta lógica com as pessoas que atendem?

Tais questões nos levam a pensar na frouxidão e nas contradições internas das diretrizes públicas, que aumentam o espaço de influência de um código moral conservador nas decisões políticas, o que implica em entraves para a aceitação da estratégia de redução de danos na atenção ao usuário de drogas. Vemos aí a necessidade de diretrizes e de políticas públicas que guiem as ações, para que estas possam ser integradas, organizadas e principalmente contínuas, tanto do ponto de vista da população atendida quanto da organização e da proteção do trabalhador que realiza o atendimento. A falta de diretrizes pode levar a um quadro de desintegração, de buscas individualizadas que produzem parcos resultados. Neste sentido se coloca a busca de formas de sustentabilidade para o trabalho dos redutores que possibilitem suportes mínimos para viabilizar uma reflexão sobre si e sua prática. Afinal, de que outra forma, senão a partir do exercício da própria cidadania, poderia o redutor veicular a tão desejada cidadania do usuário?

\section{REFERÊNCIAS}

Acselrad, G. (2000). A educação para a autonomia: a construção de um discurso democrático sobre o uso de drogas. Em G. Acselrad (Org.), Avessos do prazer: drogas, Aids e direitos humanos (pp. 161-188). Rio de Janeiro: Fiocruz.

Bastos, F., Karam, M. L. \& Martins, S. (2003). Drogas, dignidade e inclusão social: a Lei e a prática de redução de danos. Rio de Janeiro: Ministério da Saúde/Coordenação Nacional de DST e Aids/Associação Brasileira de Redutores de Danos (ABORDA).

Brasil (1976). Lei. $n^{\circ}$ 6.368, de 21 de outubro de 1976. Disponível

em:

<http://www.pgj.ce.gov.br/secretarias/secje/legislacao/6368.htm> (Acessado em 29/11/03).

Brasil (1999). Rio Grande do Sul, Projeto de Lei No. 169/99, de 12 de agosto de 1999. Disponível em: < www.al.rsgov/proposições/199/pl169_99.htm> (Acessado em 4/09/03)
Brasil (2004). Secretaria Nacional Antidrogas. Política Nacional Antidrogas. PNAD - D.O.U. No 165-27.08.2002. Brasília.

Brasil, C. (2003). A perspectiva de redução de danos com usuários de drogas: Um olhar sobre os modos éticos de existência. Dissertação de Mestrado Não-Publicada, Programa de Pós Graduação em Psicologia Social e Institucional, Universidade Federal do Rio Grande do Sul, RS.

Bueno, R. (1998). Estratégias de redução de danos em Santos, SP. Em F. Bastos, F. Mesquita, \& L. Marques. (Orgs.), Trocas de seringas: Drogas e Aids. Ciência, Debate e Saúde Pública. Brasília: Ministério da Saúde.

Câmara dos Deputados.(2004) Redação final do substitutivo da Câmara dos deputados ao Projeto de Lei n. 7.134-B, de 2002, do Senado Federal. Disponível em: http://www.camara.gov.br/Sileg/Prop_Detalhe.asp?id=66174. (Acessado em 02/07/04)

Castel, R. (1998). As metamorfoses da questão social: uma crônica do salário. (I.D. Poleti, Trad.). Petrópolis: Vozes. (Trabalho original publicado em1995).

Conte, M. (2004). A clínica psicanalítica com toxicômanos: o "corte \& costura" no enquadre institucional. São Leopoldo: UNISINOS.

Coppel, A. \& Doubre, O. (2004), Drogues: risquer une question. Vacarme, 29, 82-85.

Dreyfus, H. \& Rabinow, P. (1995). Michel Foucault entrevistado por Hubert L. Dreyfus e Paul Rabinow: sobre a genealogia da ética: uma revisão do trabalho. Em Michel Foucault, uma trajetória filosófica: para além do estruturalismo e da hermenêutica. (pp.253-278). Rio de Janeiro: Forense Universitária.

Foucault, M. (1971). Nietzsche, la généologie, l’histoire: hommage à Jean Hyppolite. Paris: PUF.

Foucault, M. (1996). Microfísica do Poder. (R. Machado, Org.). Rio de Janeiro: Graal

Foucault, M. (1997). Arqueologia do saber. (L.F.B. Neves, Trad.). Rio de Janeiro: Forense Universitária. (Trabalho original publicado em 1969).

Foucault, M. (1999). A Ordem do discurso.(L.F.A. Sampaio, Trad.). São Paulo: Edições Loyola.(Trabalho original publicado em 1971).

Foucault, M. (2001). História da sexualidade (Vol.I). A vontade de saber. (M.T.C. Albuquerque \& J.A. Albuquerque, Trads.). Rio de Janeiro: Graal. (Trabalho original publicado em 1976).

Hacker, M., Telles, P. \& Bastos, F. (2001). Uma década de pesquisas sobre usuários de drogas injetáveis \& HIV/aids no Rio de Janeiro: parte I rumo a uma epidemia sob controle?

A contribuição dos estudos multicêntricos frente a Epidemia de HIV/Aids entre UDI no Brasil: 10 anos de pesquisa e redução de danos. Série Avaliação, 8 (pp.49-78).

Heller, D., McCoy, K. \& Cunningham, C. (2004). An invisible barrier to integrating HIV primary care with harm reduction services: Philosophical clashes between the harm reduction and medical models. Public Health Report, 119(1), 32-39.

Instituto Brasileiro de Ciências Criminais - IBCCRIM, (2004). Vítimas do uso de drogas. Boletim, 11(136), 1. 
Iinsua, P. \& Moncada, S. (2003). Cognitive and behavioral change in health care professionals after training in the treatment of injection drug users. Clinic Infection Dieases, 15 (37), 416-421.

Ministério da Saúde (2001). Coordenação Nacional de DST e Aids Manual de Redução de Danos. Saúde e Cidadania. Brasília.

Ministério da Saúde (2003). A política do Ministério da Saúde para Atenção Integral a Usuários de Álcool e Outras Drogas. Brasília.

Ministério da Saúde (2004a). Portaria No. 2.1917, de 14 de outubro de 2004. Brasília.

Ministério da Saúde (2004b) - S. Parcerias. Disponível em: <http://www.aids.gov.br > (Acessado em 02/07/04)

Ministério da Saúde (2005). Portaria No. 1.187, de 13 de julho de 2005. Diário Oficial da União. Brasília.

Piccolo, F. (2001). Se deixar a droga levar... Um estudo sobre as trajetórias sociais de usuários de drogas em uma vila de Porto Alegre. Dissertação de Mestrado Não-Publicada,
Programa de Pós Graduação em Antropologia Social, Universidade Federal do Rio Grande do Sul.

Rhodes, T.; Davis, M. \& Judd, A. (2004). Hepatitis C and its risk management among drug injectors in London: renewing harm reduction in the context of uncertainty. Addiction. 99(5), 621-633.

Strike, C. J., O'Grady, C., Myers, T. \& Millson, M. (2004). Pushing the boundaries of outreach work: the case of needle exchange outreach programs in Canada. Social Sciences and Medicine. 59(1), 209-219.

Wodak, A. (1998). Redução de danos e programas de trocas de seringas. Em F. Bastos, F. Mesquita \& L. Marques (Orgs.), Trocas de seringas: drogas e Aids. Ciência, debate e saúde pública (pp.55-72). Brasília: Ministério da Saúde.

Recebido em 21/09/2004

Aceito em 30/05/2005

Endereço para correspondência: Henrique Caetano Nardi, Rua Ramiro Barcelos, 2600, CEP 90035-003, Porto Alegre-RS.

E-mail: hcnardi@aol.com 